\title{
PERCEPTION OF STUDENTS FROM BTESL TOWARDS ENHANCING VOCABULARY THROUGH SOCIAL MEDIA IN MSU
}

\author{
Mohammad Ali Al-Saggaf1, Tharshana Prabakaran1, Ali Hadi Al-Aidaros² \\ ${ }^{1}$ Management and Science University, Malaysia \\ ${ }^{2}$ Ministry of Education, Yemen \\ Corresponding author: Mohammad AliAl-Saggaf [mohammad_ali@msu.edu.my]
}

\begin{tabular}{llll}
\hline Received: 13.03 .20201 & • Accepted: 21.03.2021 & Published: 31.03 .2021 \\
\hline
\end{tabular}

\begin{abstract}
Vocabulary is fundamental and one of the important components in acquiring a second language. The implementation of various platforms and applications in carrying a lesson is another way or substitute towards enhancing the students' vocabulary knowledge. The current study aims to investigate the perceptions of students from Bachelor in Teaching English as a Second Language (BTESL) towards Enhancing Vocabulary through Social Media in Management and Science University (MSU), Malaysia. Another aim of this study is to examine the differences in the perceptions of the BTESL students towards enhancing vocabulary through social media according to the year of study. This research involves 263 BTESL students consisting of $78.1 \%$ of Female respondents and $21.9 \%$ of Male respondents. A quantitative research was used in this study by using a survey method for the data collection. The questionnaire was created after reviewing the existing related literature and the draft was given to the experts in the field of Linguistics. The data was tabulated in the SPSS software and it was interpreted through descriptive analysis. The findings affirm that majority of the students view enhancing vocabulary through social media positively and it was observed that there are differences in the students' perceptions according to the year of study. Thus, this study provides pedagogic implications to foster the teaching and learning processes based on the 21 st Century learning.
\end{abstract}

Keywords: BTESL; Enhancing Vocabulary; Social Media; Second Language; English

\section{Introduction}

In the contemporary world, achieving acceptable English vocabulary and as well as developing skills in the second language have become a challenge for students, (Al Mubarak, 2017). Vocabulary is the core and one of the important elements in learning a second language (Kabooha \& Elyas, 2015). However, the use of various platforms and applications in carrying a lesson is another way or substitute towards enhancing the students' vocabulary knowledge. As we are in the 21st century, everything around us is implemented through technology and digital based. Almost all the students, primary or secondary school students, have their own gadgets and electronic devices such as laptop, smartphones and iPad, whereby they carry their own devices everywhere with them. The use of gadgets has made the students to be actively involved and present in the Social Media. Social Media is a free application and website that enables the users to participate and engage in a social network by sharing and exchanging contents among the community. There are a lot of examples of Social Media such as Facebook, Instagram, WhatsApp, Twitter and many more. Students tend to enhance 
their vocabulary skills through the use of social media platforms. Although traditional methods are implemented in the teaching and learning processes, students tend to learn and absorb the words quickly through social media. This is because the visuals and audios that are presented on Social Media attract the students more than just listening to the lecture in the traditional classroom.

Vocabulary learning through Social Media has been broadly adopted by the educationist in numerous fields. Students do not have the opportunity to enhance their vocabulary skills because of the limited time in the traditional ESL language classes. This may hinder the student's learning processes in the ESL classroom. Nation (2005) have stated that although the teachers can teach the students individual words distinctively but willfully teaching the students vocabulary is one of the least effective ways of developing the learners' vocabulary knowledge. This is one of the reasons which make both the language teachers and the researchers to look for a different way as a method of teaching vocabulary. One of the ways which can help the ESL learners to enhance their vocabulary skills is by using the technology that we have in the 21 st century, which is the Social Media. Social media can improve and enhance the students' knowledge of the English Language, namely Vocabulary Acquisition. Taylor (2005) have stated that the fundamental role of vocabulary learning in the dimension of language learning for all the four skills which is reading, writing, speaking and as well as listening skills has been declared by a lot of second language educators. According to Mahzoun and Zohoorian (2019), studies reported that the online practicing on vocabulary learning of the language learner gave a very important effect on the students. It is interesting to understand about the vocabulary learning through social media based on the previous study.

The current study briefly investigates the perception of students from Bachelor in Teaching English as a Second Language (BTESL) towards enhancing vocabulary through Social Media in Management and Science University. The researcher will also look into the perceptions of the BTESL students from all the three groups which is Year 1, Year 2, and Year 3 towards enhancing vocabulary through social media and compare their perceptions. Based on the previous researchers, it was observed that there is limited research on enhancing vocabulary through social media among the higher education students. Thus, a research will be carried out among the higher education students in Management and Science University in Malaysia to minimize the research gap.

Today, the use of technology in teaching language and learning is very dominant and widely used among the students. The way educators teach is important not only to the students, but also to how the educators remain relevant to the field in the 21st Century. The immense popularity of social media has made new open doors for the English Language Learners, especially in Enhancing their Vocabulary, which is the backbone of any languages. Without comprehensive vocabulary knowledge, the students might experience the failure to communicate even for those who have mastery of grammar. Social media has always been the most effective way to learn and enhance vocabulary. With the increasing popularity of enhancing vocabulary through social media, it is important to gather as much information as possible on the importance of enhancing vocabulary through social media and the perception of students in it. It is important to know if the students agree with enhancing vocabulary through social media and what are the impacts to the students. The scope of this study is to investigate the perceptions of the students towards a new way of enhancing vocabulary in the learning process. The current study will be conducted in a higher education institution in Shah Alam, Malaysia among the Bachelor in Teaching English as a Second Language, BTESL students. The aim of this study is to identify the students' perceptions towards enhancing vocabulary through social media and also to study the differences in the perceptions of the BTESL 
students towards enhancing vocabulary through social media according to the year of study. In this regard, there are two research questions proposed in this study.

a. What are the perceptions of students from BTESL towards Enhancing Vocabulary through Social Media in MSU?

b. What are the differences in the perceptions of the BTESL students towards Enhancing Vocabulary through Social Media according to the year of study?

\section{Literature Review}

\subsection{Theoretical Framework}

The theoretical justifications focus on the disadvantages at where Toffoli and Sockett (2010) have stated that the online ISLL is an "unofficial, unscheduled, and impromptu," whereby it is not taking place in a formal setting or environment. It is the interaction of the learners with social media during their leisure time. The input of more than one modality which is the "Visual and Auditory" made the learners to be interested in the content and thus have the interest in understanding more towards the input. According to Krashen's (1981) comprehensible input hypothesis and Moore, Burton and Myers (2004), regarding the theory of multi-channel communication, it is stated that learning and exploring new information in a lot of modalities initiates learning. Figure 1 shows the study framework.

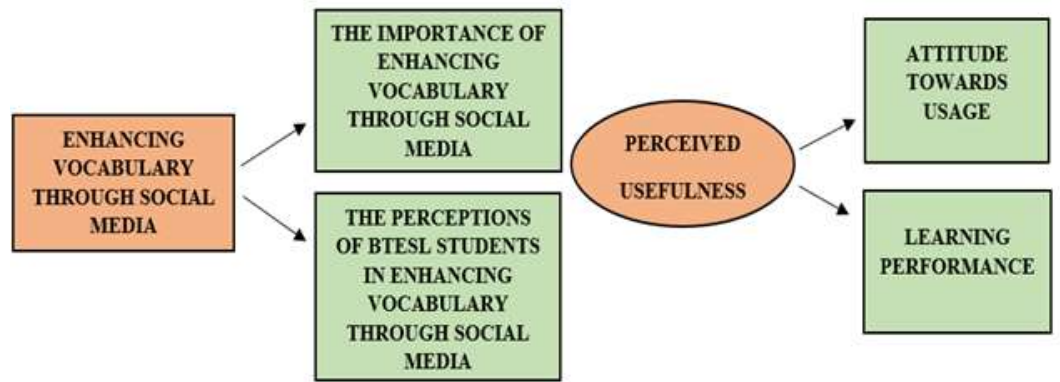

Figure 1. Study Framework

The study of Vocabulary through Social Media is supported by a lot of researchers. Blood (2000), Dyrud et al. (2005) and Kajder and Bull (2004) argued that the online blogs that is available in the World Wide Web is very useful as it can help the English Language Learners to gain some valuable information and knowledge from it by exchanging information among their peers. Enhancing Vocabulary through Social Media has a lot of significances that ease the students in the teaching and learning processes. Social Media acts as a facilitator and enhancer in learning (Tess, 2013).

Tosun (2015) confirmed that vocabulary is the backbone of any language and without a good vocabulary, people will find it hard to communicate even if their grammar is good. In another study by Kabooha and Elyas (2015) have stated that vocabulary is one of the important elements in learning a language. Therefore, students regard the usefulness of learning vocabulary through social media. Students are able to improve and perform well in their studies through the usage of social media. According to Dewing (2010) and Kaplan and Haenlein (2010) in The Use of Social Media Platforms, social media are the services and applications that keep the users engaged and communicate among each other. Social media helps the users to comment, posts and share their content. Thus, it helps the users to gain their knowledge by learning new words. 


\subsection{Vocabulary Acquisition}

In his study, Al Mubarak (2017), the researcher investigates the Sudanese Students' Perceptions of using Facebook for Vocabulary Learning at University Level. This study was carried out to explore the experiences of the Sudanese students on the use of Facebook and as well as the students' perceptions towards the influence of Facebook on their English Proficiency. This study was also carried out to fill in the gap based on the previous research. One of the gaps that have been found in the study is regarding the literature gap which is the impact of social networking sites in various ways such as enhancing, promoting, supporting teaching and learning processes (Eteokleous et al., 2012; Razak et al., 2020). The questionnaire was used as the instrument to collect the data. The questionnaire contains a total number of 12 items in it. Initially, the questionnaire was given to all the 100 students aged between 20-22 years old but however, only 85 students responded and return back the questionnaire. From the findings, out of $85 \%, 84 \%$ strongly agreed that Facebook have given a positive impact towards learning the English Vocabulary. Nine per cent of the respondent agreed to the statement while four per cent strongly disagree to the statement. Overall, the students showed a positive attitude towards the use of Facebook. For the future research, the author suggested that Facebook must be used as a tool for the English Language Learners in the online community (Shih, 2011).

Arndt and Woore (2018) highlighted the comparison between the vocabulary acquisition between two different social media platforms, which is the video blogs (YouTube videos) and written blog posts (reading blog posts). This study involves participants of 84 EFL learners who came from a different background. The participants volunteered themselves by following a call which was posted on social media sites that correlate with an online community called Nerdfighter. The method of sampling used in this study sample is the voluntary sampling. This voluntary sampling method was chosen as it was thought that the participants are more familiar and interested towards the content compared to the other sample of language learners. A browser-based web survey was used by the participants to complete the study. The findings of the article stated that there are no significant differences between the two groups. The limitation of this study is the vocabulary gain of the participants were only measured based on six targeted words (nouns, verbs and adjective). For the future research, this study suggests to include other parts of speech and compare incidental learning of the targeted words through reading and watching videos. Other than that, the durability of the learning gains from both of the two modalities needed to be compare in the future research. Since, each of the language elements has its own characteristics, a future research is needed to determine whether the findings in this study are usable to the other texts and video materials. This study suggests to use a qualitative approach in the future research so that the results will be more accurate.

Kabooha and Elyas (2018) surveyed on the effects of YouTube in multimedia instruction for vocabulary learning. This study was validated by another study done by Kabooha and Elyas (2015) have stated that vocabulary is one of the important elements in learning a language. Therefore, the aim of this study is to investigate the progress of the students in their vocabulary comprehension by implementing the YouTube application in the students' reading classes. Other than that, the purpose of this study is also to look into the perception of both the teachers and the students towards the implementation of YouTube for the students' vocabulary development. Based on the findings, the teachers and the students gave a positive feedback on how the YouTube video has helped the students to understand and enhance their vocabulary better. It was also easy for the teacher to teach the students by using the YouTube video. Alwehaibi (2015) stated that YouTube has the authenticity to boost the students' level of confidence in the teaching and learning processes. However, there are a few limitations in this study. Firstly, the participants in this study focused on the female students. The findings of the study could have been done with a mixed gender in order to get a general perception. 
In addition to that, another limitation of this study is the time constraint. For the future research, it is suggested to conduct the research with a mixed gender population, a longer time period and as well as to look into a few more English Language Institutions for a better result.

Pérez-Sabater and Montero-Fleta (2015) explored a study on ESP vocabulary and social networking: The case of Twitter. This study aimed to explore the students' level of confidence by using the microblogging tool, Twitter. This study involves students from higher education who take the English for Architecture subject. A total number of seventy-five students took the subject at the university. The investigated group were under a homogeneous group as they share the same background. The age of the participants was between 20 to 27 years old, and both the numbers of genders was equal. The students were then divided into three groups equally. Since there were three groups, the first group acted as a control group while the remaining two groups acted as the experimental group. The control group were given traditional vocabulary instructions while the other two groups were exposed to Twitter as a learning tool. Based on the findings of the study, it was stated that "Writing short sentences" in Twitter became the favourable thing to do for most of the students. However, the students could not be able to gain the benefits of using the Twitter as a learning tool, especially in terms of vocabulary acquisition. In addition to that, the students often repeat the grammatical error even when they are typing a short sentence in Twitter. It can be seen that the use of Twitter gave the students an opportunity to voice out their feelings and emotions through blogging. A Blogging App like Twitter is used to express one's thoughts and feelings in an informal way. For the future research, the researcher of this study has suggested that the prototype community of learners that is used in this study can pave the way by evaluating the motivational-cognitive dimensions for a better result.

\subsection{Enhancing Vocabulary through Social Media}

A study done by Sivagnanam and Yunus (2020) on Utilizing Social Media in Vocabulary Enhancement among Primary ESL Learners argues that the students have cooperated throughout the research and there were a lot of positive feedbacks from the students. The participants agreed that by using the social media, they are able to enhance their vocabulary knowledge. Other than that, it serves as an interactive tool for the ESL learners to learn the vocabulary. However, there are a few suggestions that can be done based on the limitation in this study. For the future research, it is suggested to increase the number of sample and focus on one specific social media platform and look at the teachers' point of view towards enhancing vocabulary through social media.

In another study conducted by Fathi, Alipour, and Saeedian (2018), found that there was positive feedback shown by the participants. The use of the "Memrise App" have shown a significant effect towards the students in the experimental group. The students were able to enhance and improve their vocabulary knowledge through the App. Furthermore, there were few studies done by other researcher towards enhancing vocabulary through social media that has shown a positive feedback. For example, Heidari Tabrizi and Onvani (2017) have stated that learning vocabulary is more useful by using the Telegram App when compared to the traditional classroom.

Followed by a research on The Use of Social Media Platforms to Enhance Vocabulary Developing in Learning a New Language: A Review of the Literature conducted by Alharthi, Bown and Pullen (2020). The aim of this study is to look into the possible role of SMP, which is the Social Media Platforms in learning vocabulary that focuses on the students' perceptions and as well as practices. This paper looks into all the review of the literature from the year 2014 to the year 2018. There were a lot of research done by the researchers during that time. Dewing (2010) and Kaplan and Haenlein (2010) stated that social media are the services and applications that keeps the users engaged and 
communicate among each other. Social media helps the users to comment, posts and share their content. Thus, it helps the users to gain their knowledge by learning new words. In this study, the researcher has found out that there are a lot of Social Media Applications such as Facebook, Instagram, Twitter and many more. People can easily connect and interact among each other through Social Media. However, the use of YouTube and WhatsApp are said to be not the helpful or useful app to the students as the main purpose of the applications are to post video rather than sharing various forms of content. The researcher of this study has also found out that the use of Facebook and Twitter is the favourite application of most of the students as they find it better to interact and communicate by using the social media application. For the future research, it is suggested to conduct and look into the research which is related to Snapchat and Instagram as there were no previous study done to this effect.

\subsection{The Usefulness of Social Media}

In the research of The Impact of Teaching through Twitter on Students' Vocabulary Learning by Alqunayeer (2016), the findings of the study showed an outstanding result in the improvement of the students' Vocabulary Knowledge. The students in the experimental group showed more interest in studying compared to the students in the control group. This is one of the reasons on why the students in the experimental group, who are exposed to the Social Networking sites, Twitter can perform better than the control group students who are taught by using the traditional method. In addition, the study also suggests that Twitter can be not only used for leisure and entertainment purposes, but it can be also used for language lessons. This study was validated by another study done by Ally and Samaka (2013) who have stated that the social media platforms like Twitter improves the students' attention, engagement and as well as participation. For the future research, Alqunayeer (2016) suggested that this research must be conducted in a different setting such as in schools. Other than that, the data can be collected by targeting the participants from different ages in order to obtain a better result in the future research.

Another study by Heriyanto (2018) reported that both the students and the teachers agree with the use of YouTube as an effective teaching aid to help the students to learn English language, especially in learning the Vocabulary. Most of the students also agree with their opinion that YouTube helps them in enhancing and improving their English comprehension. YouTube has helped the students to perceive the targeted vocabulary even better than they did before. In addition to the study, the students have also proved their opinions by saying that YouTube has helped them in learning and enhancing the targeted vocabulary by approximately about $71 \%$. This study was validated by another study done by Chun \& Plass (1996) which stated that the pictorial and verbal cues improve the students' vocabulary learning by increasing the recall and the retention. For the future research, Heriyanto (2018) suggested that the same experimental study must be taken by using the mixed gender by using a larger sample and the study must be done in the other institutions as well, not only focus on one specific institution for a better result.

Followed by a research on The Role of Social Media in Development of English Language Vocabulary at University Level conducted by Khan, Ayaz and Faheem (2016). This study supports other studies done by Blood (2000), Dyrud et al. (2005) and Kajder and Bull (2004), who stated that the available online blogs that is available in the World Wide Web is very useful as it can help the English Language Learners to gain some valuable information and knowledge from it by exchanging information among their peers. The main objective of this research is to study the role of social media in learning vocabulary at the university level, to look into the teachers' perception of the usage of social media in learning vocabulary and as well as to suggest on how to implement the usage of social media in learning vocabulary at the university level. Khan, Ayaz and Faheem (2016) conducted this research 
by using the descriptive study. This study involves of 36 University Teachers who were chosen by using the random sampling technique. All the 36 teachers were teaching English Language Subjects for the graduate levels at affiliated colleges and also at the University of Science \& Technology Bannu. The teachers were either teaching functional or compulsory English language. The instruments used in this study are the self-made questionnaires which are prepared by the researcher itself to collect the data from all the 36 teachers. The validity and the reliability of this research are then found out by statistically analysing the data which is collected from the participants. There were 13 questions included in the questionnaires. Most of the questions asked are about the role of social media in vocabulary learning at the university level, the interest of the students in learning vocabulary through social media and the benefits and usefulness of learning vocabulary to the students through social media. The findings of the study have stated that the role of social media in learning vocabulary is dominant at the university level. This is because social media such as Facebook, Instagram and many more helps the students in mastering the vocabulary knowledge, which is very helpful for the students. For the future research, there are major drawbacks that need to be looked into as more extensive research needs to be carried out in this field.

\section{Materials and Methods}

\subsection{Research Design}

A quantitative research method was adopted in this study to investigate the perceptions of the BTESL students towards Enhancing Vocabulary through Social Media in Management and Science University, MSU. The outcome of this research is further determined by the numerical content. In the current study, the researcher has used a survey research methodology to collect the respective data about the perceptions of the students towards Enhancing Vocabulary through Social Media. The collected data will be descriptively analysed.

\subsection{Sample}

The participants in this study are the Bachelor in Teaching English as a Second Language, (BTESL) students which comprises of Year 1, Year 2 and Year 3 BTESL students from Management and Science University, Shah Alam, Malaysia. The number of populations of BTESL students from Year 1, Year 2 and Year 3 is 830 students. Based on the 95\% confidence level and 5\% margin of error, only 263 respondents participated in this study. The type of sampling method that is used in this research is the stratified sampling method to identify the number of population and thus divide the population into smaller groups. Therefore, students from BTESL Year 1, Year 2 and Year 3 were asked to answer the online questionnaire that was distributed to them on WhatsApp.

\subsection{Instrument}

The instrument that is used in this study is a questionnaire. After reviewing the existing related literature, the researcher has found out that there is no such a survey is ready available and thus developed a clear understanding of the context and the necessary items that can be used to collect the necessary data to answer the research questions set for the purpose of this study. The questionnaire consists of two sections whereby the first section consists of the students' background information such as gender, age, and the year that they are in; whereas the second section of the questionnaire consist of questions about the students' perception in Enhancing Vocabulary through Social Media and there are 15 items in total. The items were measured by using a 5 Point-Likert scale which is $1=$ Strongly disagree, $2=$ Disagree, $3=$ Neutral, $4=$ Agree, $5=$ Strongly agree. The first draft was given to two experts 
in the field of Linguistics at the department of education, School of Education and Social Sciences, MSU Malaysia. The draft was also given to one of the experts outside from MSU. The experts reviewed the draft survey items and the overall structure of the survey. All the necessary amendments were done as per the experts' feedback. This draft has been tested in a pilot study for reliability checking.

\subsection{Pilot Study}

A pilot study was carried out in this research in order to test the validity and the reliability of the respective questionnaire. This is to ensure that all the questions in the questionnaire are suitable, clear, and reliable for the main study. The questionnaire was distributed to all the targeted students and the researcher was able to receive around 51 respondents in total. However, the researcher conducted the pilot study by using only 30 respondents from the data that have been collected. The collected data were then converted into numerical forms, and it was further analysed by using the SPSS software, version 26. The value of the Cronbach's Alpha for all the (15) items based on the data collected from the 30 respondents is 0.884 as shown in Table (1).

Table 1: Reliability of the Instrument

\begin{tabular}{lll}
\hline \multicolumn{3}{c}{ Reliability of the Instrument } \\
\hline Cronbach's Alpha & Cronbach's Alpha Based on Standardized Items & N of Items \\
\hline .884 & .887 & 15 \\
\hline
\end{tabular}

\subsection{Procedures and Data Analysis}

The data was collected through the distribution of the online survey questionnaire to the targeted participants, which is the Year 1, Year 2 and Year 3 BTESL students. Once the result of the pilot study attained the reliability and the validity of the current research, the questionnaire was distributed for about two weeks through the social media platforms such as WhatsApp, Facebook, and Instagram by including the link to the Google form. The data collected for this study were then analysed by using the Statistical Package for Social Sciences, SPSS (version 26). The descriptive statistics and mean scores are used to analyze the data in this research.

\section{Results and Discussion}

There were a total number of 263 respondents from BTESL Year 1, Year 2 and Year 3. All the respondents are from Management and Science University, Shah Alam. The researcher chooses to conduct the research by using the BTESL students as the targeted sample in this study is because the BTESL students will not learn vocabulary but instead they will learn and practise on how to teach the students vocabulary. In order for the BTESL students to teach vocabulary, they must have a satisfactory vocabulary skill so that it will not obstruct the teaching and learning processes. The questionnaire that is used in this study was in the form of an online survey and it was distributed to the BTESL students through social media platforms. The data was analysed by using the Statistical Package for the Social Sciences (SPSS) version 26 to obtain the frequency and the mean scores. The mean scores were used to compare and differentiate the students' perceptions towards enhancing vocabulary through social media according to the year of study. 


\subsection{Demographic Information}

Both Male and Female participated in this research. The frequency of the female respondents is higher than the male respondents. The percentage of the female respondents is $78.1 \%$ (205) whereas the percentage of the male respondents is $21.9 \%$ (58) as shown in Figure (1). The majority respondents in this research are female as there are a lot of female students in the BTESL course compared to the male students. The total number of BTESL students who answered the questionnaire is 263 .

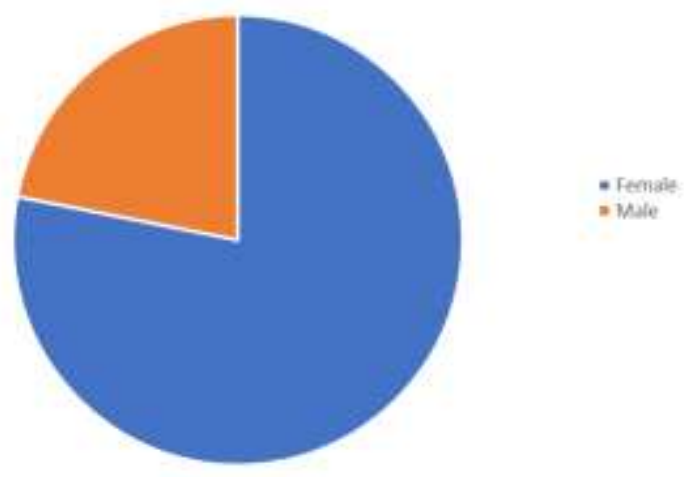

Figure 1. Female/Male Percentage

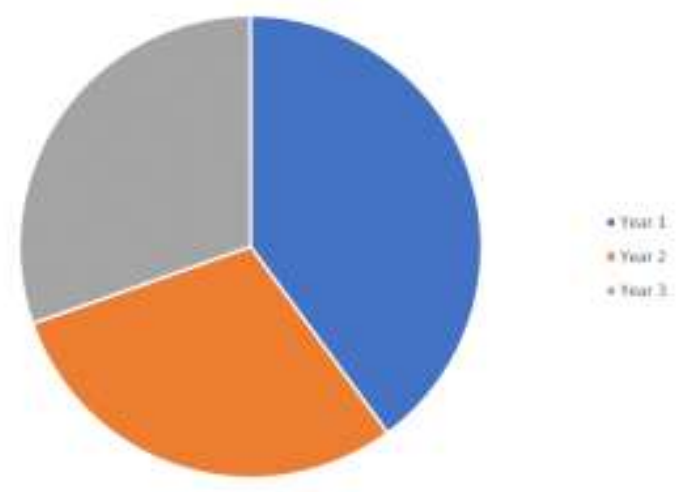

Figure 2. Year of Study of the Participants

As stated in Figure (2), the respondents come from three different years of study, which is BTESL Year 1, BTESL Year 2 and BTESL Year 3. The Bachelor in Teaching English as a Second Language, BTESL course is a three years programme. Therefore, the researcher distributed the online questionnaire equally to the participants of all the three years of study and looked into their perceptions towards enhancing vocabulary through social media. According to Figure (2), it shows that there are quite a number of equal respondents from all the three years but however it is observed that the percentage of Year 1 respondents are the highest compared to the percentage of Year 2 respondents and Year 3 respondents. There were 104 respondents from Year 1 (39.5\%), 78 respondents from Year $2(29.7 \%)$ and 81 respondents from Year $3(30.8 \%)$.

\subsection{Students' Perceptions towards Enhancing Vocabulary through Social Media}

This section presents the findings of the perception of the students towards using social media to enhance their vocabulary. The findings are shown in Table 2 below. 
Table 2: Overall Students' Perceptions towards Enhancing Vocabulary through Social Media

Item Mean

Deviation

1. I am interested in using social media as an educational tool

\begin{tabular}{|c|c|c|}
\hline 3.86 & .994 & 263 \\
\hline 4.03 & .971 & 263 \\
\hline 4.01 & 1.04 & 263 \\
\hline 3.75 & 1.07 & 263 \\
\hline 3.95 & .995 & 263 \\
\hline 3.86 & 1.08 & 263 \\
\hline 3.56 & 1.12 & 263 \\
\hline 3.77 & 1.04 & 263 \\
\hline 3.84 & 1.05 & 263 \\
\hline 3.52 & 1.07 & 263 \\
\hline 3.71 & 1.02 & 263 \\
\hline 3.37 & 1.20 & 263 \\
\hline 3.60 & .963 & 263 \\
\hline 2.84 & .997 & 263 \\
\hline 3.60 & 1.01 & 26 \\
\hline
\end{tabular}

2. I find it very useful to use social media to enhance my vocabulary knowledge

3. I have learned a lot of new vocabularies through social media

4. I had to look up to new words in social media to enhance my vocabulary knowledge

5. I was able to learn vocabulary better in social media when it was presented in various ways. (e.g., Visuals, audio)

6. Learning vocabulary through social media is more fun and less stress compared to learning vocabulary in class

7. I am able to enhance my vocabulary knowledge more in social media compared to classroom

8. Using social media is very effective for me as I am able to learn and enhance my vocabulary knowledge

9. I am interested to use social media as it helps me in enhancing my vocabulary knowledge

10. I am able to achieve better results by learning new vocabularies through social media

11. I make use of newly learnt vocabulary through social media sites on a daily basis

12. I use social media platforms to enhance my vocabulary knowledge

13. I think that teachers should emphasize more on learning vocabular through social media

14. I find it hard to learn vocabulary in the classroom

15. I prefer learning vocabulary through social media platforms like YouTube, Facebook and Instagram.

Table 2 shows the total mean scores for all the 15 items in the questionnaire. The overall mean score for the students' perceptions towards enhancing vocabulary through social media is 3.68 , which is high. This shows that the BTESL students views enhancing vocabulary through social media positively.

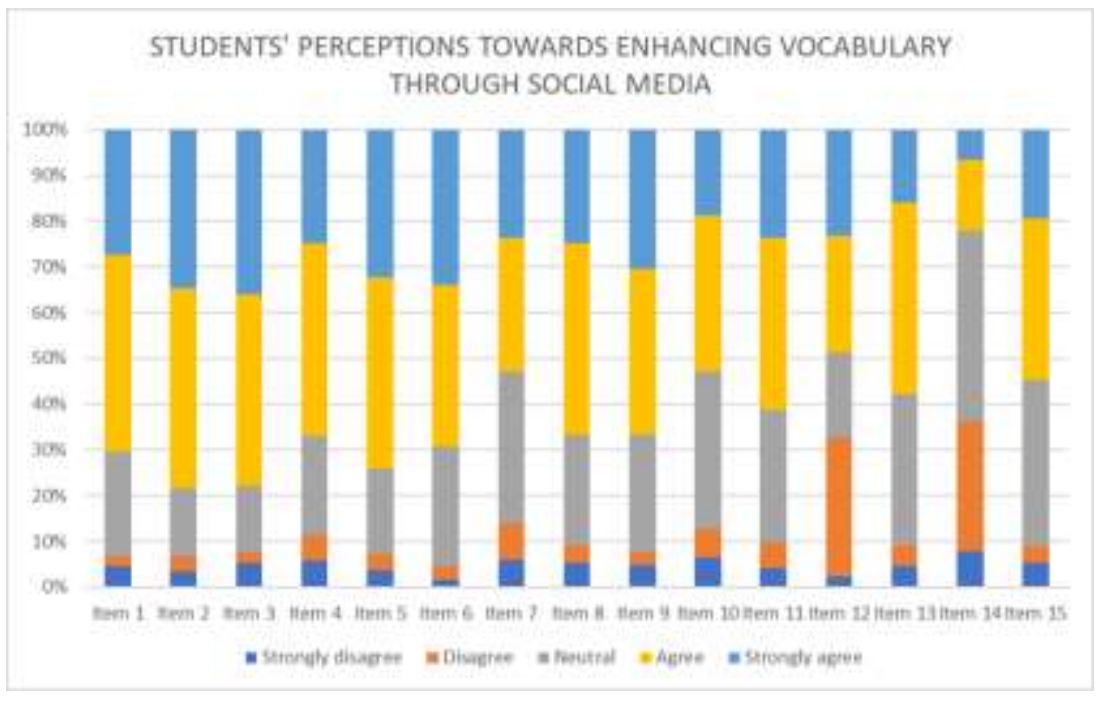

Figure 3. Students' feedback on social media to improve vocabulary learning 
Figure 3 is based on the first research question in this study. The students gave a positive feedback towards Enhancing Vocabulary through Social Media as the scale 'Agree' was acquired as the highest percentage for all the 15 items presented. The respondents from BTESL Year 1, Year 2 and Year 3 viewed Social Media as a useful and productive platform for them to enhance their vocabulary skills. Social media is important as it acts as an entertainment platform and also works as an educational tool for students. Moreover, Social Media motivates the students to learn better and create an engagement among their peers, Mahzoun and Zohoorian (2019). The students from Year 1, Year 2 and Year 3 have stated that they have learned a lot of new vocabularies through social media (Item 3) and there were no students from Year 1 who 'Disagree' to this item. Therefore, it affirms that the BTESL Year 1 students have enhance their vocabularies more than the BTESL Year 2 and Year 3 students.

Besides, the findings of the result reveals that the students use most of their time in social media to look up for new words (Item 4). The majority of the students from BTESL Year 1, Year 2 and Year 3 'Agree' to the item as social media introduces the students with new and bombastic vocabularies which might be helpful to the students. In addition to that, students affirm that they were able to learn vocabulary better in social media when it was presented in various ways such as visuals and audio. Sight and sound elevate the students' learning experiences (Singh, 2005).

Veletsianos and Navarrete (2012) proved that students are fond of using social media applications for learning purpose as it is supportive and helpful. In the traditional classroom, students will have to listen and depend on the teacher's lectures to learn and enhance their vocabulary but through social media platforms, students are skilled to develop and enhance their vocabulary skills independently. Besides, the students pointed out that they were able to achieve better results by learning new vocabularies through social media (Item 10) as it receives one of the highest percentages of the 'Agree' scale compared to the other items in this study.

\subsection{Differences in the students' perceptions towards Enhancing Vocabulary through Social Media according to the year of study}

Table 3: Top 5 items with the highest mean score according to BTESL Year 1 students

\begin{tabular}{clcc}
\hline No. & Items & Count & Mean Value \\
\hline 1 & $\begin{array}{l}\text { I find it very useful to use social media to enhance my vocabulary } \\
\text { knowledge }\end{array}$ & 104 & 4.29 \\
2 & $\begin{array}{l}\text { I have learned a lot of new vocabularies through social media } \\
3\end{array} \quad \begin{array}{l}\text { I was able to learn vocabulary better in social media when it was } \\
\text { presented in various ways (e.g., Visuals, audio) }\end{array}$ & 104 & 4.22 \\
4 & $\begin{array}{l}\text { I am interested in using social media as an educational tool } \\
\text { I am interested to use social media as it helps me in enhancing my } \\
\text { vocabulary knowledge }\end{array}$ & 104 & 3.03 \\
&
\end{tabular}

Table 3 shows the top 5 items with the highest mean score according to BTESL Year 1 students. The findings affirms that majority of the Year 1 students find it very useful to use social media to enhance their vocabulary knowledge as the statement received the highest mean value compared to the other items which is 4.29 . The students have also agreed that they were able to learn a lot of new vocabularies through social media and they were able to learn them better when it was presented in various ways such as visuals and audio. Most of the BTESL Year 1 students are interested in using social media as an educational tool as it helps them to enhance their vocabulary knowledge. The average mean value that the BTESL Year 1 students achieve for all the 15 items is 3.78 . 
Table 4: Top 5 items with the highest mean score according to BTESL Year 2 students

\begin{tabular}{cllc}
\hline No. & Items & Count & Mean Value \\
\hline 1 & $\begin{array}{l}\text { I was able to learn vocabulary better in social media when it was } \\
\text { presented in various ways (e.g., Visuals, audio) }\end{array}$ & 78 & 3.91 \\
2 & I have learned a lot of new vocabularies through social media & 78 & 3.82 \\
3 & Learning vocabulary through social media is more fun and less & 78 & 3.80 \\
& stress when compared to learning vocabulary in class & & \\
4 & I am interested in using social media as an educational tool & 78 & 3.76 \\
5 & Using social media is very effective for me as I am able to & 78 & 3.74 \\
& learn and enhance my vocabulary knowledge & & \\
\hline
\end{tabular}

Table 4 shows the top 5 items with the highest mean score according to BTESL Year 2 students. Majority of the Year 2 students have stated that they were able to learn vocabulary better when it was presented in Visuals and audio as the item achieved the highest mean score compared to the other items which is 3.91. Besides, similar to the Year 1 students, the Year 2 students have also agreed that they have learned a lot of new vocabularies through social media. Apart from that, the Year 2 students feel that Learning vocabulary through social media is more fun and less stress when compared to learning vocabulary in class. Most of the students are interested in using social media as it is effective for them to learn and enhance their vocabulary knowledge. The average mean value that the BTESL Year 2 students achieve for all the 15 items is 3.61 .

Table 5: Top 5 items with the highest mean score according to BTESL Year 3 students

\begin{tabular}{clcc}
\hline No. & Items & Count & Mean Value \\
\hline 1 & $\begin{array}{l}\text { I find it very useful to use social media to enhance my vocabulary } \\
\text { knowledge }\end{array}$ & 81 & 3.98 \\
2 & I have learned a lot of new vocabularies through social media & 81 & 3.93 \\
3 & $\quad$ I was able to learn vocabulary better in social media when it was & 81 & 3.90 \\
& presented in various ways (e.g., Visuals, audio) & & 3.84 \\
4 & I am interested in using social media as an educational tool & 81 & 3.83 \\
5 & $\quad$ I am interested to use social media as it helps me in enhancing & 81 & \\
& my vocabulary knowledge & & \\
\hline
\end{tabular}

Table 5 shows the top 5 items with the highest mean score according to BTESL Year 3 students. It can be clearly seen that majority of the Year 3 students find it very useful to use social media to enhance their vocabulary knowledge as the item obtained the highest mean value compared to the other items which is 3.98. The Year 3 students agreed that they have learned a lot of new vocabularies through social media and they were able to learn it even better when it was presented in various ways such as Visuals and audios. Moreover, the students affirms that they are interested to use social media as it helps them in enhancing their vocabulary knowledge. The average mean value that the BTESL Year 3 students achieve for all the 15 items is 3.64 . 


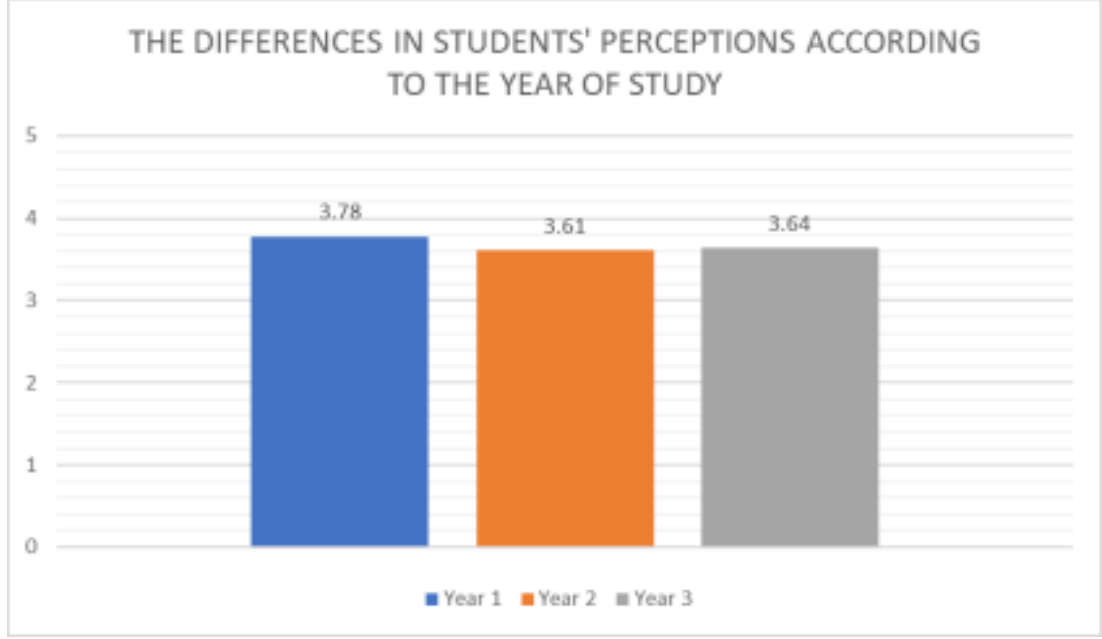

Figure 4. Perception differences according to year of study

Figure 4 is based on the second research question in this study. It has been noticed that there are differences in the mean value according to the year of study, which is BTESL Year 1, Year 2 and Year 3. Thus, this reveals that the second research question have been answered. The average mean value for Year 1 is 3.78, Year 2 is 3.61 and Year 3 is 3.64. Hence, it shows that the Year 1 students viewed enhancing vocabulary through social media positively, followed by Year 3 and Year 2 BTESL students. There are some similarities in the Year 2 and Year 3 students' perceptions, but the average mean value in the students' perceptions for the Year 1 students showed some differences. Different programme structure according to the year of study could be one of the reasons for the differences in the students' perceptions towards enhancing vocabulary through social media. In the Bachelor in Teaching English as a Second Language (BTESL) course, the subjects that are offered to the students varies based on the year of study. The subjects that are offered to the Year 1 students focuses more on the linguistics and the grammar item. One of the subjects that the Year 1 students learn is "Introduction to General Linguistics". As this subject focuses in-depth on the language item such as syntax, pragmatics and semantics, the Year 1 students may have felt the necessary to enhance their vocabulary so that they can strengthen their vocabulary knowledge as it will ease the students in understanding the nature of the subject as learning vocabulary is vital in acquiring a language, whether it is a second language or foreign language (Folse, 2004; Mehring, 2005).

Followed by the Year 3 students who have a different subject offered to them compared to Year 1 students. The subjects that are offered to the Year 3 students focuses more on the heavy subjects such as Research Methodology and Research Project. Since the students have to develop more of their writing skills, they must have a rich vocabulary knowledge. Vocabulary is an asset to an individual, those who have a good vocabulary are able to communicate well and engage in a community, Anderson and Freebody (1981). Besides, the subjects that are offered to the Year 2 students are quite technical, such as the "English Phonetics and Phonology". In this subject, the students must be well aware of the techniques and format to answer the questions. It requires the students to understand and memorize some of the content in the subject. Hence, the Year 2 students may not have the necessary to enhance their vocabulary through social media.

Moreover, the implementation of Social Media and ICT through assignments and projects might be one of the reasons for the students to view this study positively. Teachers assign the students assignments and projects, in such the students will have to use and integrate social media to complete their task. Since the Year 1 students are new to the course, they might use the social media platforms to find information that is related to their assignments and projects for the particular subject. Aside 
from that, the Year 3 students will be working on heavy subjects like Research Methodology and Research Project. As mentioned earlier, the students will have to use technologies such as the Social Media Applications to find research articles, to distribute their survey for research purposes and many more. This could be one of the reasons for the Year 3 students to enhance their vocabulary knowledge through social media. As mentioned, the subjects that are offered to the Year 2 students are quite technical, which is why it shows the differences in the mean value for the Year 2 students.

\section{Conclusion and Implications}

Overall, it can be clearly seen that all the research questions in this study have been answered and viewed positively by the BTESL students. Vocabulary is the backbone of any languages. Without having a good vocabulary knowledge, one cannot engage and communicate well in a discourse community. In addition to that, vocabulary is important to all the students, especially to the Bachelor in Teaching English as a Second Language (BTESL) students. The BTESL course is structured in such a way that the students will be trained and polished well to be a good mentor and an educator to the students in the future. As we are in the 21st century, technology has changed our lives in many ways. It has impacted and influenced the education system and allows access to many sources and applications. One of them is the use of Social Media in the education system. Social media is a wide and broad network that allows the users to communicate and engage among one another through comments, blogs, posts and many more. Furthermore, the use of Social Media tends to enhance and expand the students' vocabulary knowledge as there are millions of references in it. Students' perceptions towards enhancing vocabulary through social media was the main focus in this study. Moreover, the students' perceptions were also compared according to the year of study in order to examine if there is any significant difference in their perceptions. It was observed that the students viewed this study positively based on the responses given by the students in the previous chapters. Besides, there were also differences in the students' perceptions according to the year of study.

In conclusion, it is important to cope and adapt with the $21^{\text {st }}$-century learning, and educators are highly encouraged to take a step and plan strategically beforehand. Educators must be aware of the education system and the changes that have been made to it so that the learning process will be smooth and successful and it meets the students' needs.

To obtain a deeper insight of the students' perceptions towards enhancing vocabulary through social media, future researchers need to conduct a qualitative research that provides a more flexible approach compared to the quantitative research. Other than that, the sample of the study needs to be expanded and focus on students from different courses, especially the Male respondents. For the future research, it is suggested to conduct the research by looking into the teachers' perceptions or point of view towards enhancing vocabulary through social media as it may vary from the current research.

\section{References}

Alharthi, M., Bown, A., \& Pullen, D. (2020). The use of social media platforms to enhance vocabulary developing in learning a new language: a review of the literature. Arab World English Journal (AWEJ) Special Issue on CALL, (6).

Ally, M., \& Samaka, M. (2013). Open education resources and mobile technology to narrow the learning divide. International Review of Research in Open and Distributed Learning, 14(2), 14 27. 
Al Mubarak, A. A. (2017). SUDANESE STUDENTS'PERCEPTIONS OF USING FACEBOOK FOR VOCABULARY LEARNING AT UNIVERSITY LEVEL. Journal of Nusantara Studies (JONUS), 2(1), 170-176.

Alqunayeer, H. S. (2016). The impact of teaching through Twitter on students' vocabulary learning: A case study of Qassim University. World Journal of English Language, 6(2).

Alwehaibi, H. O. (2015). The impact of using Youtube in EFL classroom on enhancing EFL students' content learning. Journal of College Teaching \& Learning (TLC), 12(2), 121-126.

Anderson, R. C., \& Freebody, P. (1981). Vocabulary knowledge. Comprehension and teaching: Research reviews, 77-117.

Arndt, H. L., \& Woore, R. (2018). Vocabulary learning from watching YouTube videos and reading blog posts. Language Learning \& Technology, 22(3), 124-142.

Blood, R. (2002). We've got blog introduction. EDITORS of Perseus Publishing. We've got blog. Cambridge, MA: Perseus Publishing.

Dewing, M. (2010). Social media: An introduction (Vol. 1). Ottawa: Library of Parliament.

Dyrud, M. A., Worley, R. B., \& Flatley, M. E. (2005). Blogging for enhanced teaching and learning. Business Communication Quarterly, 68(1), 77-80.

Eteokleous, N., Ktoridou, D., Stavrides, I., \& Michaelidis, M. (2012). Facebook-a social networking tool for educational purposes: developing special interest groups. ICICTE 2012 Proceedings, 363-375.

Fathi, J., Alipour, F., \& Saeedian, A. (2018). Enhancing Vocabulary Learning and Self-regulation via a Mobile Application: An Investigation of the Memrise App. Journal of Modern Research in English Language Studies, 5(1), 27-46.

Folse, K. S. (2004). The underestimated importance of vocabulary in the foreign language classroom. CLEAR news, 8(2), 1-6.

Heriyanto, D. (2018). The Effectiveness of Using Youtube for Vocabulary Mastery. ETERNAL (English Teaching Journal), 6(1).

Kabooha, R., \& Elyas, T. (2015). The impacts of using YouTube videos on learning vocabulary in Saudi EFL classrooms. In ICERI 2015 Conference (pp. 3525- 3531).

Kabooha, R., \& Elyas, T. (2018). The Effects of YouTube in Multimedia Instruction for Vocabulary Learning: Perceptions of EFL Students and Teachers. English Language Teaching, 11(2), 72-81.

Kajder, Sara, Glen Bull, and Emily Van Noy. "A Space for." Learning \& Leading with Technology 31.6 (2004): 32-35.

Kaplan, A. M., \& Haenlein, M. (2010). Users of the world, unite! The challenges and opportunities of Social Media. Business horizons, 53(1), 59-68.

Khan, I. U., Ayaz, M., \& Faheem, M. (2016). The role of social media in development of English language vocabulary at university level. International Journal of Academic Research in Business and Social Sciences, 6(11), 590-604.

Krashen, S. D. (1981). Second language acquisition and second language learning. University of Southern California. 
Mahzoun, F. E., \& Zohoorian, Z. (2019). EMPLOYING TELEGRAM APPLICATION: LEARNERS'ATTITUDE, VOCABULARY LEARNING, AND VOCABULARY DELAYED RETENTION. European Journal of Foreign Language Teaching.

Mehring, J. G. (2005). Developing vocabulary in second language acquisition: From theories to the classroom. Retrieved January, 7, 2015.

Nation, I. S. P. (2011). Research into practice: Vocabulary. Language Teaching, 44(4), 529-539.

Pérez-Sabater, C., \& Montero-Fleta, B. (2015). ESP vocabulary and social networking: The case of Twitter. Ibérica, Revista de la Asociación Europea de Lenguas para Fines Específicos, (29), 129154.

Razak, N. A., Yassin, A. A., \& Maasum, T. N. R. T. M. (2020). Formalizing Informal CALL in Learning English Language Skills. In Enhancements and Limitations to ICT-Based Informal Language Learning: Emerging Research and Opportunities (pp. 161-182). IGI Global.

Shih, R. C. (2011). Can Web 2.0 technology assist college students in learning English writing? Integrating Facebook and peer assessment with blended learning. Australasian Journal of Educational Technology, 27(5).

Singh, Y. (2005). Instructional Technology in Education. Darya ganj new Delhi.

Sivagnanam, S., \& Yunus, M. M. (2020). Utilizing Social Media in Vocabulary Enhancement among Primary ESL Learners. Universal Journal of Educational Research, 8(2), 490-498.

Toffoli, D., \& Sockett, G. (2010). How non-specialist students of English practice informal learning using web 2.0 tools. ASp. la revue du GERAS, (58), 125-144.

Tess, P. A. (2013). The role of social media in higher education classes (real and virtual)-A literature review. Computers in human behavior, 29(5), A60-A68.

Tosun, S. (2015). The effects of blended learning on EFL students' vocabulary enhancement. Procedia-Social and Behavioural Sciences, 199(1), 641-647.

Veletsianos, G., \& Navarrete, C. (2012). Online social networks as formal learning environments: Learner experiences and activities. The International Review of Research in Open and Distributed Learning, 13(1), 144-166. 